\title{
Cadmium-induced ER stress and inflammation are mediated through C/EBP-DDIT3 signaling in human bronchial epithelial cells
}

\author{
Jeeyoung Kim ${ }^{1,2,5}$, Haengseok Song ${ }^{3,5}$, Hye-Ryeon Heo ${ }^{1,2,5}$, Jung Woon Kim ${ }^{1,2}$, Hye-Ryun Kim ${ }^{3}$, \\ Yoonki Hong ${ }^{1,2}$, Se-Ran Yang ${ }^{4}$, Seon-Sook Han ${ }^{1,2}$, Seung-Joon Lee ${ }^{1,2}$, Woo Jin Kim ${ }^{1,2}$ and Seok-Ho Hong ${ }^{1,2}$ \\ Cadmium (Cd), a major component of cigarette smoke, disrupts the normal functions of airway cells and can lead to the \\ development of various pulmonary diseases such as chronic obstructive pulmonary disease (COPD). However, the molecular \\ mechanisms involved in Cd-induced pulmonary diseases are poorly understood. Here, we identified a cluster of genes that are \\ altered in response to $\mathrm{Cd}$ exposure in human bronchial epithelial cells (BEAS-2B) and demonstrated that Cd-induced ER stress \\ and inflammation are mediated via CCAAT-enhancer-binding proteins (C/EBP)-DNA-damaged-inducible transcript 3 (DDIT3) \\ signaling in BEAS-2B cells. Cd treatment led to marked upregulation and downregulation of genes associated with the cell cycle, \\ apoptosis, oxidative stress and inflammation as well as various signal transduction pathways. Gene set enrichment analysis \\ revealed that $\mathrm{Cd}$ treatment stimulated the C/EBP signaling pathway and induced transcriptional activation of its downstream \\ target genes, including DDIT3. Suppression of DDIT3 expression using specific small interfering RNA effectively alleviated \\ Cd-induced ER stress and inflammatory responses in both BEAS-2B and normal primary normal human bronchial epithelial cells. \\ Taken together, these data suggest that C/EBP signaling may have a pivotal role in the early induction of ER stress and
} inflammatory responses by $\mathrm{Cd}$ exposure and could be a molecular target for $\mathrm{Cd}$-induced pulmonary disease.

Experimental \& Molecular Medicine (2017) 49, e372; doi:10.1038/emm.2017.125; published online 1 September 2017

\section{INTRODUCTION}

Chronic obstructive pulmonary disease (COPD) is a major cause of morbidity and mortality, the prevalence of which is increasing worldwide. ${ }^{1,2} \mathrm{COPD}$ is characterized by progressive airway obstruction with chronic and irreversible inflammation of the airways and lung tissues, as a result of prolonged exposure to inhaled irritants such as cigarette smoke. ${ }^{1}$ Long-term cigarette smoking is the most significant and commonly encountered risk factor for COPD. Chronic inflammation caused by cigarette smoke in COPD patients likely has an important role in the pathogenesis of lung cancer. ${ }^{3}$

Cadmium (Cd), a major component of cigarette smoke, has a significant impact on lung function and might be associated with the development of COPD by disrupting homeostasis in the endoplasmic reticulum (so-called ER stress) and subsequent pro-apoptotic signaling. ${ }^{4-6}$ Therefore, understanding the molecular alterations initiated by $\mathrm{Cd}$ exposure to lung tissue is essential to prevent and manage the development of COPD. The ER is the primary intracellular organelle for proper protein synthesis, folding and assembly. ER stress triggers an evolutionarily conserved intracellular response called the unfolded protein response (UPR), which is initiated by the activation of ER stress transducers including inositol-requiring enzyme 1, protein kinase RNA-like ER kinase and activating transcription factor (ATF) 6. Binding immunoglobulin protein (BiP) has a central role in ER stress signaling. Upon ER stress, the release of these transducers from BiP triggers the UPR, which regulates the balance between cell survival and apoptosis. ${ }^{7,8} \mathrm{Cd}$ induces cell death, apoptosis and DNA damage through ER stress-triggered UPR in several cell types. For example, $\mathrm{Cd}$ can induce DNA damage by activating the ER stress response in hepatocarcinoma cells. ${ }^{9} \mathrm{Cd}$ also induces neuronal cell death by the generation of reactive oxygen species (ROS) followed by disruption of ER homeostasis. ${ }^{10}$ However,

\footnotetext{
${ }^{1}$ Department of Internal Medicine, School of Medicine, Kangwon National University, Chuncheon, South Korea; ${ }^{2}$ Environmental Health Center, Kangwon National University Hospital, Chuncheon, South Korea; ${ }^{3}$ Department of Biomedical Science, College of Life Science, CHA University, Seongnam, South Korea and ${ }^{4}$ Department of Thoracic and Cardiovascular Surgery, School of Medicine, Kangwon National University, Chuncheon, South Korea ${ }^{5}$ These authors contributed equally to this work.

Correspondence: Dr S-H Hong, Department of Internal Medicine, School of Medicine, Kangwon National University, Kangwondaehakgil-1, Chuncheon, Gangwon-do 24341 South Korea.

E-mail: shhong@kangwon.ac.kr

Received 26 December 2016; revised 28 March 2017; accepted 29 March 2017
} 
the molecular mechanisms involved in Cd-induced ER stress and apoptotic pathways in human bronchial epithelial cells have not been fully elucidated.

To investigate the genes and cellular pathways related to Cd-induced cytotoxicity in human bronchial epithelial cells (BEAS-2B), we compared the gene expression profiles of $\mathrm{Cd}(10$ and $30 \mu \mathrm{M})$-treated BEAS-2B cells to those of non-treated control cells. A number of genes associated with cell proliferation, apoptosis, oxidative stress and inflammation, as well as various signal transduction pathways, were affected by $\mathrm{Cd}$ exposure to BEAS-2B cells. Transcriptomic analysis using a functional enrichment assay revealed that $\mathrm{Cd}$ treatment stimulated the CCAAT-enhancer-binding protein (C/EBP) signaling pathway and induced the transcriptional activation of its downstream target genes, including DNA-damagedinducible transcript 3 (DDIT3, also called CHOP). DDIT3 is known as an ER-mediated pro-apoptotic factor, which is activated by cytotoxic materials and leads to cell death. ${ }^{11}$ However, the role of DDIT3 in relation to Cd toxicity in bronchial epithelial cells has not yet been clarified. Here, we show that the suppression of DDIT3 expression alleviates Cd-induced inflammatory and ER stress responses in BEAS-2B and primary normal human bronchial epithelial (NHBE) cells, suggesting that C/EBP-DDIT3 signaling could be a molecular target for COPD therapy.

\section{MATERIALS AND METHODS}

\section{Cell culturing}

The human bronchial epithelial cell line (BEAS-2B) was kindly provided by the Biomedical Research Institute at Seoul National University Hospital. BEAS-2B cells were maintained in defined keratinocyte serum-free medium containing epidermal growth factor, $100 \mathrm{U} \mathrm{ml}^{-1}$ penicillin, and $100 \mu \mathrm{g} \mathrm{ml}^{-1}$ streptomycin (Thermo Fisher Scientific, Waltham, MA, USA). Primary NHBE cells (CC-2540, Lonza Group, Allendale, NJ, USA) isolated from the epithelial lining of airways above the bifurcation of a normal human donor lung were cultured in Bronchial Epithelial Growth Medium (BEGM BulletKit medium, CC-3171, Lonza) and used before passage 3 in all experiments. Cell cultures were incubated at $37^{\circ} \mathrm{C}$ in humidified atmosphere containing $5 \% \mathrm{CO}_{2}$.

\section{Chemicals}

Unless otherwise indicated, all heavy metals were obtained from Sigma-Aldrich (St Louis, MO, USA). All reagents were freshly dissolved in sterile water at a concentration of $100 \mathrm{~mm}$ and were diluted in medium to reach the indicated concentration.

\section{Cell viability assay}

BEAS-2B cells (10 000 cells per well) were plated in a 96-well plate and allowed to attach overnight. Cells were grown to $80 \%$ confluence and then were either sham-exposed or treated with different concentrations of heavy metals $(0,1,5,10,30,50$ and $100 \mu \mathrm{M})$ to determine subtoxic doses in vitro. The cells were treated with the heavy metals for $24 \mathrm{~h}$ and replaced with fresh medium followed by further incubation for $3 \mathrm{~h}$. Cell viability was measured by MTS assay (Abcam, Cambridge, UK) according to the manufacturer's protocol. Incubation with $\mathrm{Cd}$ at $30-100 \mu \mathrm{m}$ markedly decreased cell viability at $24 \mathrm{~h}$. Thus, we performed all experiments with the concentration of 10 and $30 \mu \mathrm{m}$ of $\mathrm{Cd}$, which has been employed in many studies to examine early genetic alteration and inflammatory responses. ${ }^{10,12-15}$

\section{Western blotting analysis}

Cell lysates were separated on an SDS-PAGE gel (10\% or $15 \%)$, transferred onto polyvinyldiflouride (PVDF) membranes (Millipore, Billerica, MA, USA), and blocked with 3\% skim milk. Membranes were probed with primary antibodies against anti-human IL-1 $\beta$ antibody (AF-201-NA, R\&D Systems, Minneapolis, MN, USA), anti-IL-6 antibody (\#12153S, CST, Danvers, MA, USA), anti-human COX2 antibody (SC-1745, Santa Cruz Biotechnology, Dallas, TX, USA), anti-human iNOS antibody (ab15323, Abcam), ER stress sampler kit antibodies (\#9956S, CST), NF-kB sampler kit antibodies (\#9936, CST), anti-PTEN antibody (\#9952, CST), anti-AKT and phospho-AKT ${ }^{\text {Ser473/Thr308 }}$ antibodies (\#33748, \#11054 and \#11055, Signalway Antibody, College Park, MD, USA) or anti- $\beta$-actin antibody (\#4970P, CST) overnight at $4{ }^{\circ} \mathrm{C}$. The membranes were further probed with HRP-conjugated secondary anti-sera (A9917, A6667, or A5420, Sigma-Aldrich, St Louis, MO, USA) and visualized with PierceFast western blot kit (Thermo Fisher Scientific) and a cooled CCD camera System (Bio-Rad Laboratories, Hercules, CA, USA).

\section{ELISA}

To quantitate secreted IL-6, culture supernatants from BEAS-2B cells were measured using the human IL-6 Quantikine ELISA Kit (R\&D Systems). The ELISA plates were read using a microplate reader (Molecular Devices, Sunnyvale, CA, USA).

\section{RNA extraction and real-time $\mathrm{qPCR}$}

BEAS-2B cells $\left(2 \times 10^{6}\right.$ cells per well $)$ in 6 -well culture plates were treated in the absence or presence of Cd (Sigma) for $24 \mathrm{~h}$. Total RNA was extracted using Trizol (Life Technologies, Carlsbad, CA, USA) and reverse-transcribed to first-stand complementary DNA (cDNA) using a random primer (9-mer) and QuantiTect reverse transcriptase (Qiagen, Hilden, Germany) according to the manufacturer's protocols. Transcripts were quantitated using Power SYBR Green PCR (Applied Biosystems by Life Technologies, Warrington, UK) and the QuantStudio 6 Flex Real-Time PCR system (Applied Biosystems). Quantitation was normalized to $18 \mathrm{~s}$ rRNA (internal control). Quantitative RT-PCR was performed using the primer sequences in Supplementary Table 1 .

\section{Microarray and data analysis}

Following Cd treatment (10 and $30 \mu \mathrm{m}$ ) for $24 \mathrm{~h}$, BEAS-2B cells were collected as described previously, and the total RNA was extracted using Trizol. Affymetrix Primeview Arrays (Affymetrix) were hybridized with cRNA probes at the GenoCheck core facility (Ansan, Kyunggi, Korea). The expression value and detection calls were computed from the raw data and gene set enrichment analysis (GSEA) version 4.0 (Broad Institute, Cambridge, MA, USA) to interpret expression profiles from microarrays. ${ }^{16,17}$ GSEA was originally developed to identify cohorts of genes whose functions are integrated into certain biological processes and/or specific signaling pathways. Pathways were ranked according to the significance of the enrichment, and the validation mode measure of significance was used to identify pathways of greatest enrichment. Significance was tested by comparing the observed enrichment with the enrichment seen in data sets in which sample labels were randomly permutated $(n=1000)$. 

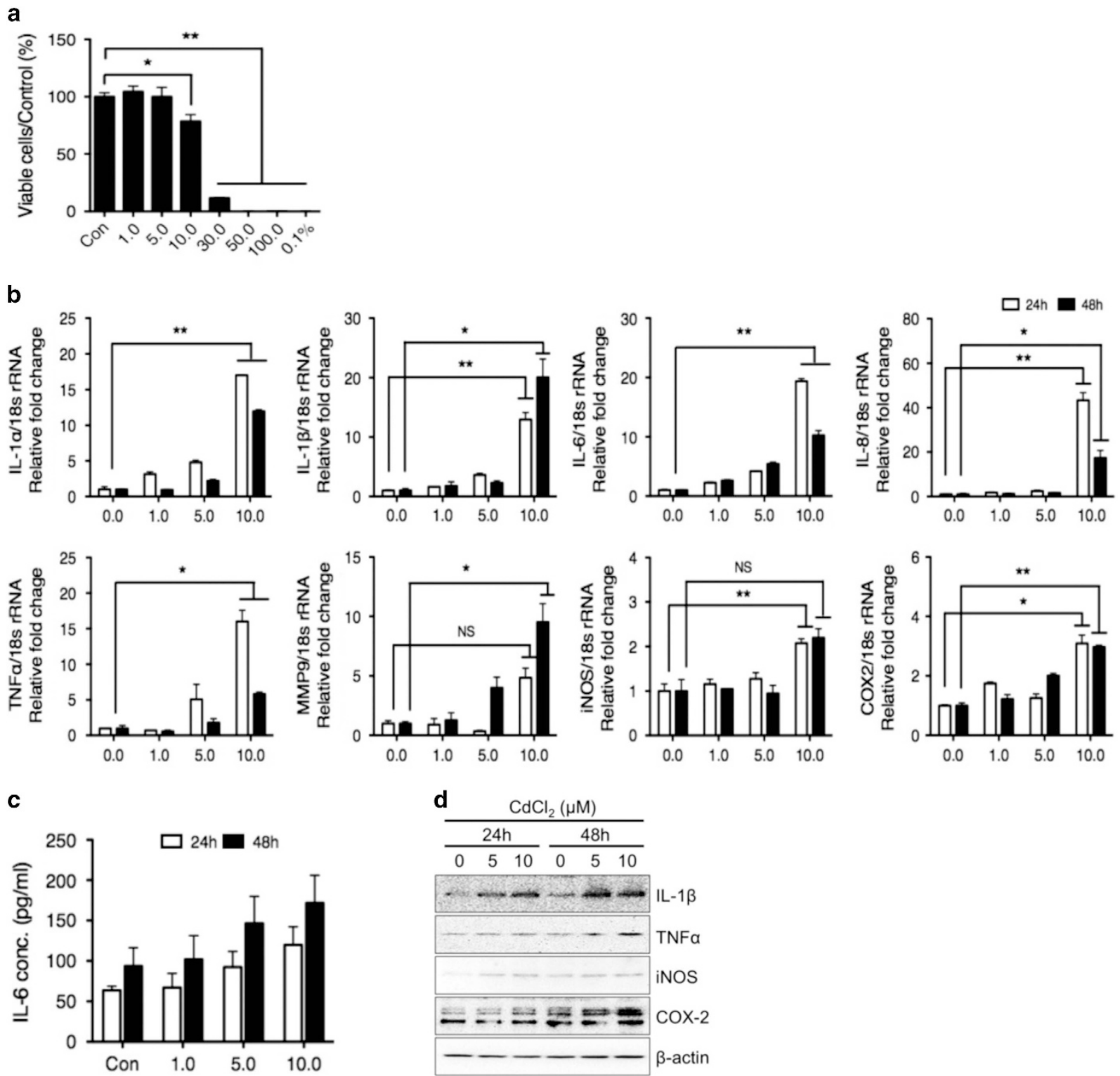

Figure 1 Effect of cadmium (Cd) on cell viability and pro-inflammatory cytokine expression. BEAS-2B cells were treated with Cd ( 1 to $100 \mu \mathrm{M}$ ) in medium containing antibiotics and incubated for 24 or $48 \mathrm{~h}$. Cell viability was measured by the MTS assay. Triton X-100 $(0.1 \%$, Triton), as suggested by the manufacturer, leads to complete cell death, and so the Triton-treated group was set as $0 \%$ of the survival rate and non-treated group sets as 100\% (a). Transcriptional levels of pro-inflammatory cytokines (IL-1 $\alpha$, IL-1 $\beta$, IL-6, IL-8, TNF $\alpha$, MMP9, COX2 and iNOS) were analyzed using SYBR green-based quantitative real-time PCR (b). Supernatant IL- 6 levels were measured by enzyme-linked immunosorbent assay (ELISA) (c). Protein levels of pro-inflammatory cytokine (IL-1 $\beta$, TNF $\alpha$, IL-6, iNOS or COX2) were detected by immunoblotting (d). All data shown are representative of three biological replicates. ${ }^{*} P<0.05 ;{ }^{* *} P<0.01$.

Gene sets consisting of $<15$ or more than 500 genes were filtered out by gene set size filters.

\section{Knockdown of DDIT3 transcript using siRNA transfection} BEAS-2B cells were transfected with human DDIT3 siRNA (DDIT3 ON-TARGET plus SMART pool) or a negative control siRNA (ON-TARGET plus non-targeting pool) at a final concentration of $10 \mathrm{~nm}$ in the presence of DharmaFECT reagent (Dharmacon, Lafayette, CO, USA), as per the manufacturer's protocol. After transfection, the cells were collected at 24 or $48 \mathrm{~h}$ for qPCR analysis and western blotting performed. All experiments were performed in triplicate, and siRNA knockdown efficiency was confirmed by qPCR.

\section{Statistical analyses}

Statistical analyses were performed with one-way ANOVA for multiple groups using GraphPad Prism (GraphPad Software, San Diego, CA, USA). $P$-values are indicated in the figures.

\section{RESULTS}

Effects of Cd on the viability and inflammatory response of human BEAS-2B cells

To evaluate the toxic effects of $\mathrm{Cd}$ on bronchial epithelial cells, the viability of BEAS-2B cells exposed to various concentrations for $24 \mathrm{~h}$ was measured using the 3-(4,5-dimethylthiazol-2-yl)- 
a
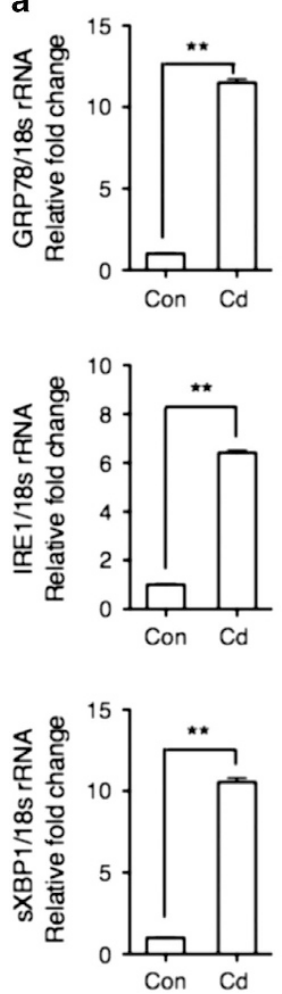
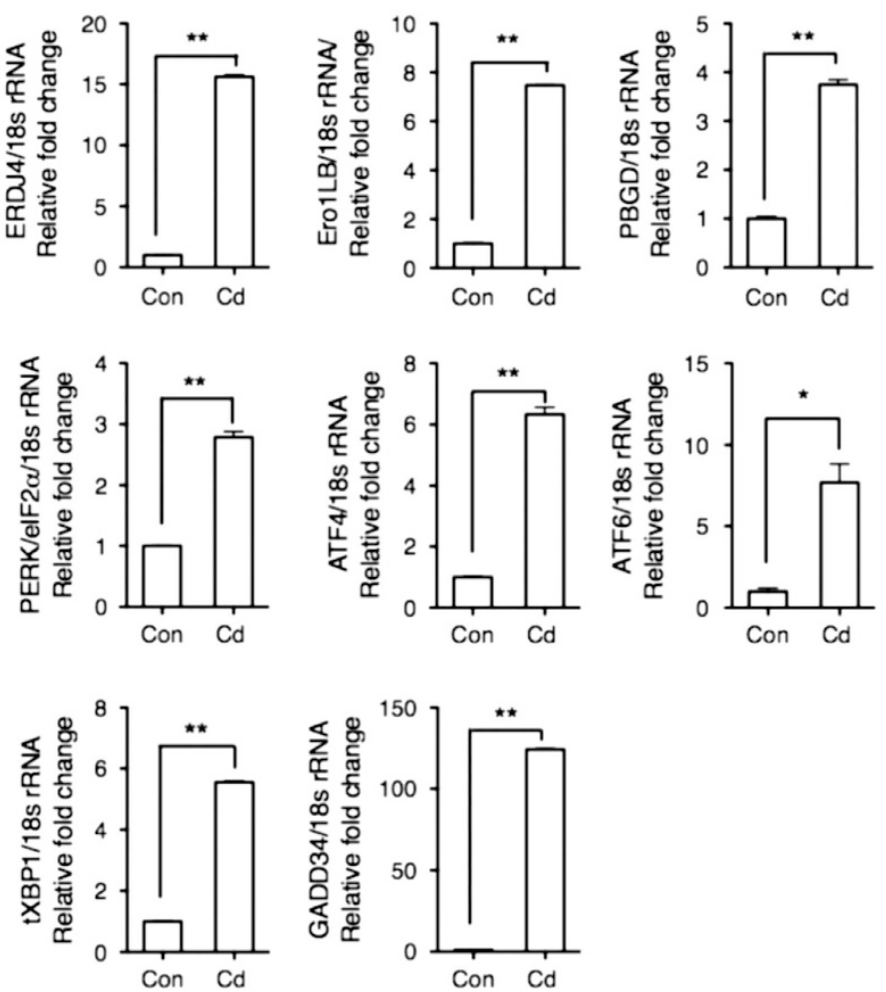

b

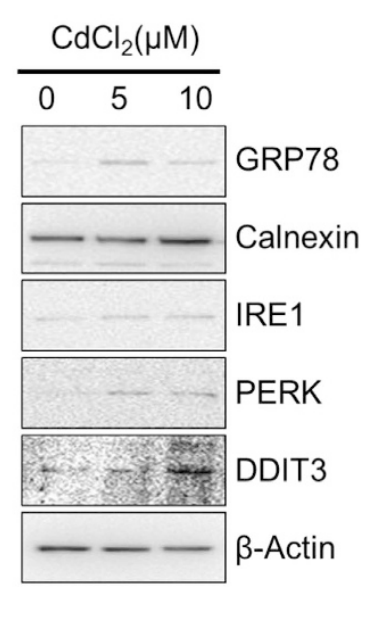

Figure 2 Effect of cadmium (Cd) on endoplasmic reticulum (ER) stress-related gene expression. BEAS- $2 \mathrm{~B}\left(2 \times 10^{5}\right.$ cells per well for qPCR and immunoblotting) were treated with the indicated concentrations of Cd (1-10 $\mu \mathrm{m})$. Levels of transcripts for GRP78, ERDJ4, Ero1LB, PBGD, IRE1, PERK/eIF2 $\alpha$, ATF4, ATF6, sXBP1, XBP1 and GADD34 were analyzed using SYBR green-based quantitative real-time PCR. Data represent the mean \pm s.e.m for three biological replicates. ${ }^{*} P<0.05 ;{ }^{*} P<0.01$ (a). Effects of Cd on the levels of ER stress-related proteins were detected by western blotting (b). All data shown are representative of at least three biological replicates.

5-(3-carboxymethoxyphenyl)-2-(4-sulfophenyl)-2H-tetrazolium (MTS) assay. A significant toxic effect of $\mathrm{Cd}$ on viability was observed in cells treated with $10 \mu \mathrm{M}$, but not in cells treated with lower doses $(1$ and $5 \mu \mathrm{M})$ of $\mathrm{Cd}$ (Figure 1a). To further confirm the cytotoxicity of other heavy metals, BEAS-2B cells were treated with various concentrations of $\mathrm{PbCl}_{2}(\mathrm{~Pb}), \mathrm{Cr}_{2} \mathrm{Na}_{2} \mathrm{O}_{7} \mathrm{H}_{2} \mathrm{O}(\mathrm{Cr})$, $\mathrm{NaAsO}_{2}$ (As) and $\mathrm{NiCl}(\mathrm{Ni}) . \mathrm{Cr}, \mathrm{Ni}$ and As tended to have a higher cytotoxic effect than $\mathrm{Cd}$, whereas $\mathrm{Pb}$ did not alter cell viability (Supplementary Figure S1). On the basis of the results of the MTS assay, we investigated whether Cd could induce the secretion of pro-inflammatory cytokines and mediators at the transcriptional and translational levels under our experimental conditions. We found that $\mathrm{Cd}$ upregulates the transcription of pro-inflammatory cytokines and mediators (such as interleukin $[\mathrm{IL}]-1 \alpha, \mathrm{IL}-1 \beta$, IL-6, IL-8, tumor necrosis factor $[\mathrm{TNF}] \alpha$, matrix metalloproteinase [MMP]9, cyclooxygenase [COX]-2 and inducible nitric oxide synthase [iNOS]) and stimulates their secretion in a dose-dependent manner (Figure 1b-d). These findings suggest that inhalation exposure to $\mathrm{Cd}$ is related to the early development of lung diseases by promoting inflammatory responses.

Cd impairs ER homeostasis and induces ER stress in human BEAS-2B cells

It is known that toxic heavy metals can impair ER homeostasis and induce UPR via ER stress. ${ }^{5,6,9,10}$ Therefore, we investigated whether Cd could induce ER stress in human bronchial epithelial cells. Real-time PCR results showed that transcript levels of GRP78, ERDJ4, Ero1LB, PBGD, IRE1, PERK/eIF2 $\alpha$, ATF4, ATF6, sXBP1, XBP1 and GADD34, which are canonical markers of UPR and ER stress, were significantly increased by treatment with $10 \mu \mathrm{M} \mathrm{Cd}$ (Figure 2a). We further found that protein levels of UPR markers (GRP78, Calnexin, IRE1, PERK and DDIT3) were also increased upon Cd treatment (Figure 2b). Collectively, these results suggest that Cd treatment promotes ER stress by disrupting ER homeostasis in human bronchial epithelial cells, which may impair normal metabolism and lead to bronchial epithelial cell death.

\section{Cd alters genome-wide gene expression profiles in human BEAS-2B cells}

To further understand Cd-induced alterations in bronchial epithelial cells at the molecular level, we asked whether $\mathrm{Cd}$ exposure alters global gene expression in human bronchial epithelial cells. The expression profiles of total RNA of BEAS-2B cells exposed to $\mathrm{Cd}(10$ and $30 \mu \mathrm{M})$ for $24 \mathrm{~h}$ were analyzed using a cDNA microarray with 49293 human cDNA probes, in an attempt to obtain a comprehensive view of the harmful effects of $\mathrm{Cd}$. Unsupervised hierarchical clustering clearly showed that the global expression patterns of BEAS-2B cells were significantly altered by $\mathrm{Cd}$ treatment in a 
dose-dependent manner (Figure 3a). A total of 1851 (1158 upregulated and 693 downregulated) and 5186 genes (2439 upregulated and 2747 downregulated) were significantly altered $(>1.5$-fold) upon treatment with 10 and $30 \mu \mathrm{M} C d$, respectively. GSEA provided heat maps that represent lists of the top 50 genes showing the greatest increase and decrease in expression upon Cd treatment (Figure $3 \mathrm{~b}$ ). Interestingly, many subtypes of metallothionein (MT) including MT1A, MT1F,
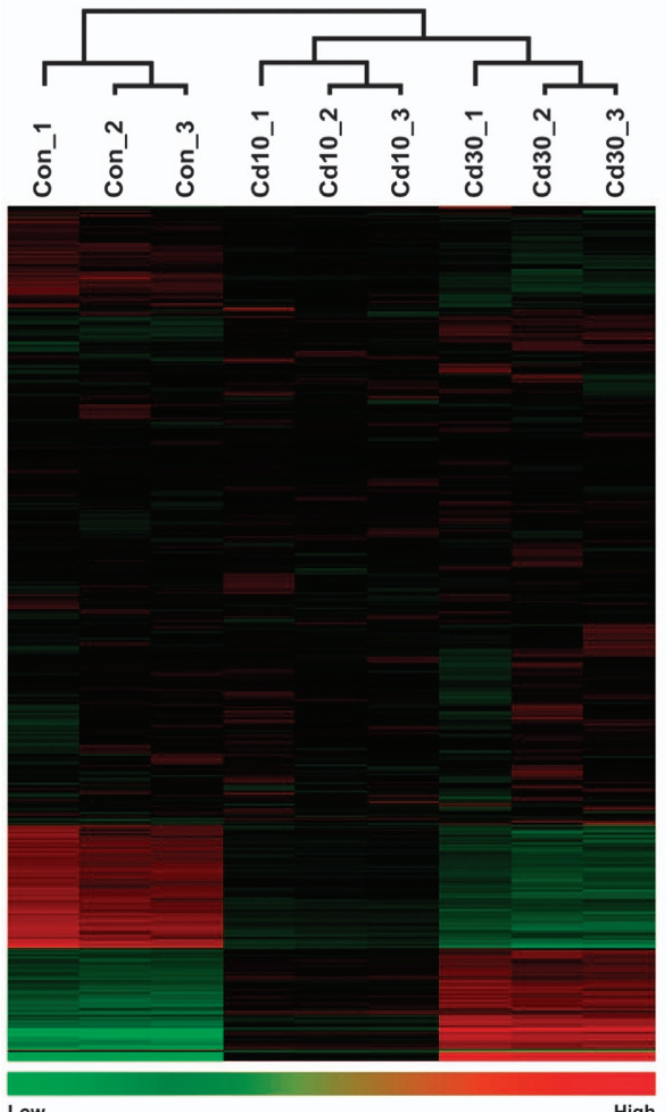

c

Con vs Cd10

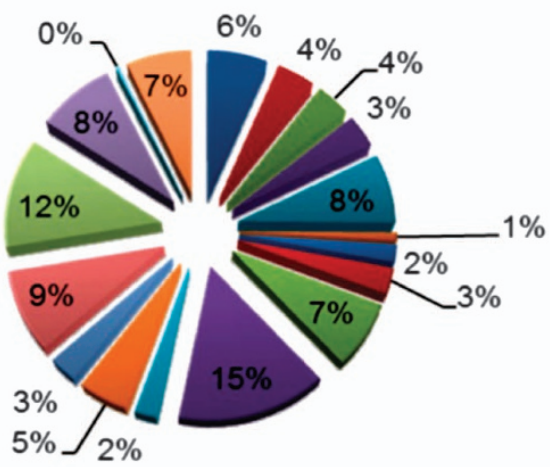

b
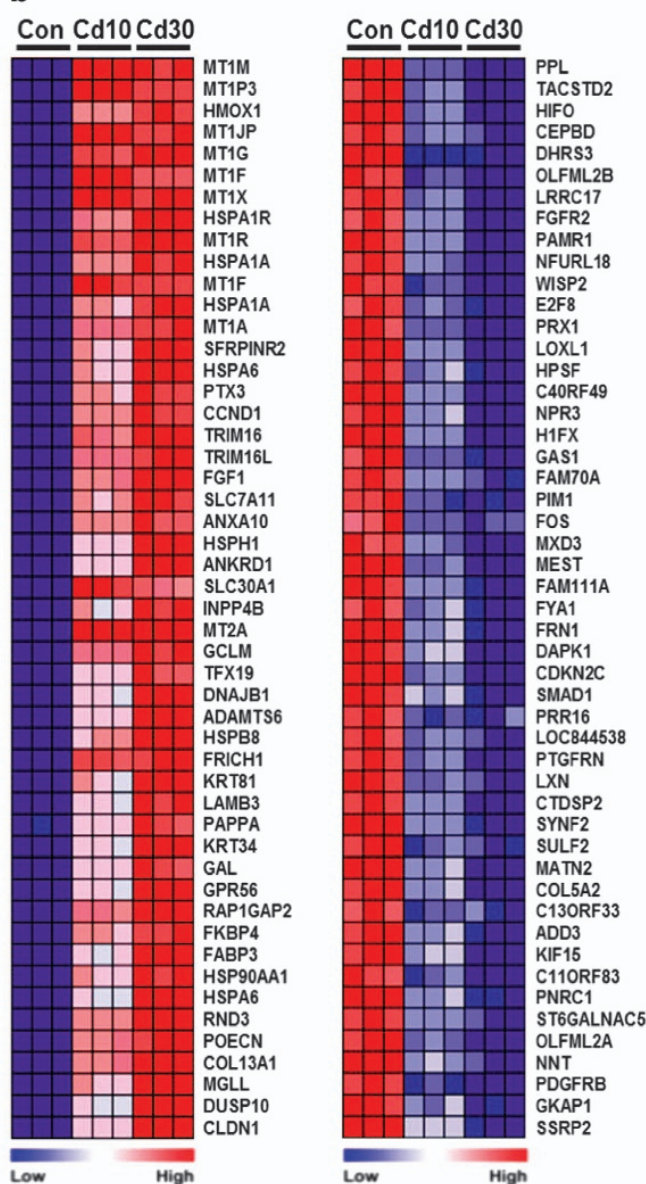

Apoptosis

Behavior

Cell adhesion

- Cell cycle

- Cell differentiation

- Cell division

- Cell growth

a Cell migration

Cell proliferation

Development

Homeostasis

$\square$ Immune response

a Lipid metabolism

口 Response to stress

$\square$ Signal transduction

- Transcription

- Translation

$\square$ Transport

Figure 3 Dysregulated genome-wide expression profiles of cells exposed to cadmium (Cd). Unsupervised hierarchical clustering analysis of cDNA microarray data from Cd-treated cells. The color spectrum from green to red indicates low to high expression (a). Heat maps for the 50 genes with the greatest increase and decrease in expression in Cd-treated cells. The color spectrum from blue to red represents low to high expression (b). Gene ontology (GO) analyses for genes that are differentially regulated in cells treated with 10 and $30 \mu \mathrm{m}$ Cd. Differentially expressed genes upon $\mathrm{Cd}$ exposure were filtered using the selection criteria of fold-change $\geqslant 1.5$ (c). Cd and Con indicate cells cultured with and without $\mathrm{Cd}$, respectively. 
Table 1 Upregulated gene sets in Cd-treated BEAS-2B cells

\begin{tabular}{lrr}
\hline Name & Size & Nominal P \\
\hline HDAC1_AND_HDAC2_TARGETS_UP & 157 & 0.000 \\
CEBP_TARGETS & 86 & 0.000 \\
NRG1_SIGNALING_UP & 143 & 0.000 \\
RESPONSE-TO-SALIRASIB_UP & 228 & 0.000 \\
INFLAMMATORY_RESPONSE_LECTIN_VS_LPS_UP & 418 & 0.000 \\
EGF_RESPONSE_48O_HELA & 148 & 0.000 \\
HRAS_ONCOGENIC_SIGNATURE & 185 & 0.000 \\
ANGIOIMMUNOBLASTIC_LYMPHOMA_DN & 109 & 0.000 \\
HYPOXIA_VIA_KDM3A & 44 & 0.000 \\
IL2_SIGNALING_UP & 76 & 0.000 \\
CYTOKINE_CYTOKINE_RECEPTOR_INTERACTION & 86 & 0.000 \\
MAPK_SIGNALING_PATHWAY & 167 & 0.000 \\
NEUROACTIVE_LIGAND_RECEPTOR_INTERACTION & 57 & 0.000 \\
AMINO_SUGAR_AND_NUCLEOTIDE-SUGAR_METABOLISM & 0.000 \\
NOD_LIKE_RECEPTOR_SIGNALING_PATHWAY & 38 & 0.000 \\
\hline
\end{tabular}

\section{Table 2 Downregulated gene sets in Cd-treated BEAS-2B} cells

\begin{tabular}{lrcc}
\hline Name & Size & Nominal P & FDR P \\
\hline EARLY_T_LYMPHOCYTE_UP & 86 & 0.000 & 0.000 \\
RESPONSE_TO_SALIRASIB_DN & 308 & 0.000 & 0.000 \\
ADIPOGENESIS_3 & 93 & 0.000 & 0.000 \\
REGULATED-BY-METHYLATION_DN & 111 & 0.000 & 0.000 \\
GAMMA_RADIATION_RESPONSE & 36 & 0.000 & 0.000 \\
BREAST_CANCER_CLUSTER_2 & 31 & 0.000 & 0.000 \\
ERYTHROID_DIFFERENTIATION & 71 & 0.000 & 0.000 \\
LEUKEMIC_STEM_CELL_DN & 141 & 0.000 & 0.001 \\
EGFR_SIGNALING_24HR_DN & 236 & 0.000 & 0.001 \\
METASTASIS_UP & 194 & 0.000 & 0.003 \\
HDAC1_AND_HDAC2_TARGETS_DN & 159 & 0.000 & 0.015 \\
GLUTAMINE_DEPRIVATION_UP & 31 & 0.007 & 0.023 \\
RESPONSE_TO_ANDROGEN_DN & 191 & 0.000 & 0.032 \\
CELL_CYCLE & 115 & 0.000 & 0.026 \\
ECM_RECEPTOR_INTERACTION & 46 & 0.014 & 0.227 \\
TGF_BETA_SIGNALING_PATHWAY & 59 & 0.021 & 0.227 \\
\hline
\end{tabular}

MT1G and MT2A that provide protection against metal toxicity were collectively upregulated. To assess the biological relevance of these differentially expressed genes (DEGs), gene ontology (GO) analyses were performed using total expression data from BEAS-2B cells treated with $\mathrm{Cd}$. The main GO categories that included DEGs were response to stress, immune response, apoptosis, cell differentiation and proliferation, development, transcription, transport and signal transduction (Figure 3c).

The C/EBP-regulated pathway is aberrantly stimulated by Cd To understand in detail the underlying mechanisms by which Cd affects cell homeostasis, it is essential to identify aberrantly regulated signaling pathways and biological processes. GSEA, a supervised analysis, showed that various signaling pathways were either upregulated or downregulated in the Cd-treated cells (Tables 1 and 2). For example, the 'TGF- $\beta$ _signaling_pathway' gene set was significantly downregulated and the 'NRG1_signaling_up' gene set was upregulated in Cd-treated cells (Supplementary Figure S2). Interestingly, gene sets consisting of target genes of histone deacetylase 1 (HDAC1) and HDAC2 were collectively either upregulated or downregulated by $\mathrm{Cd}$, suggesting that $\mathrm{Cd}$ treatment mimics the action(s) of HDACs (Supplementary Figure S2). Furthermore, the 'C/EBP_targets' gene set is significantly upregulated in Cd-treated cells. As Cd-induced inflammatory responses in BEAS-2B cells are mediated, at least in part, by ER stress and C/EBP transcript factors are associated with ER stress, we further investigated the downstream target genes of C/EBP transcription factors in cells treated with $\mathrm{Cd}$. The heat map and enrichment plot of genes in the 'C/EBP targets' gene set showed that most hits in ranking order were enriched in the area of Cd treatment (Figure $4 \mathrm{a}$ and b), suggesting that many genes associated with the C/EBP signaling pathways are upregulated in cells exposed to Cd. Real-time reverse transcription polymerase chain reaction (RT-PCR) validated that a set of genes regulated by C/EBPs, including GADD45b/g, regulator of G-protein signaling 2 (RGS2), BCL2associated athanogene 3 (BAG3) and DDIT3, was systemically upregulated by $\mathrm{Cd}$ (Figure 4c). Among all members of the $\mathrm{C} / \mathrm{EBP}$ family, $\mathrm{C} / \mathrm{EBP} \gamma$ was the most significantly increased upon treatment with 10 and $30 \mu \mathrm{M} \mathrm{Cd}$ ( twofold) (Figure $4 \mathrm{~d}$ ). In addition, $\mathrm{Cd}$ induced a moderate increase in C/EBP $\beta$. These findings collectively suggest that Cd triggers ER stress-mediated inflammatory responses in human bronchial epithelial cells via the C/EBP signaling pathway.

\section{Cd induces inflammatory cytokine secretion in human bronchial epithelial cells via the C/EBP-DDIT3 signaling pathway}

Previous studies demonstrated that DDIT3 induces cell death and inflammation in several cell types. ${ }^{10,11}$ To substantiate the 
a

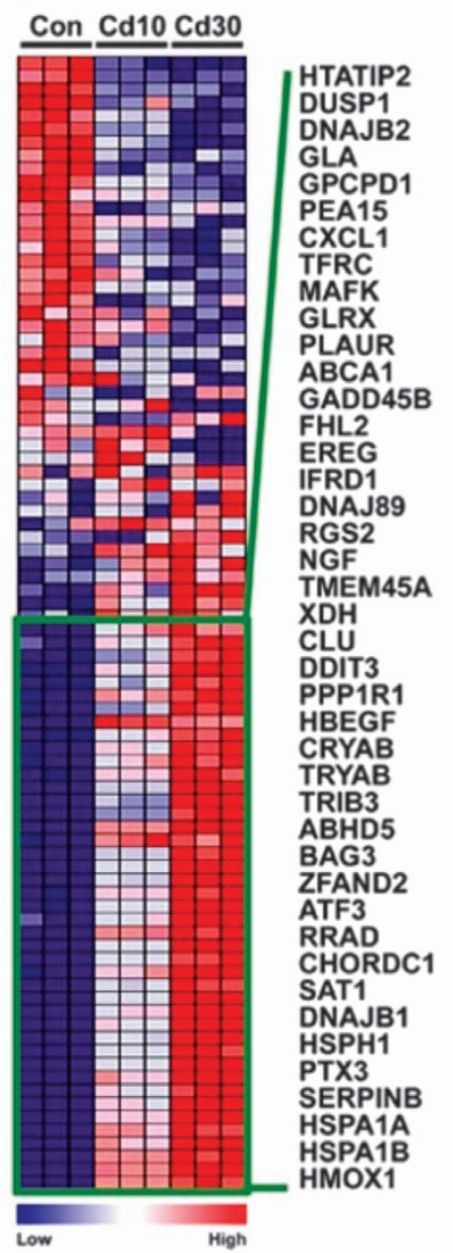

b

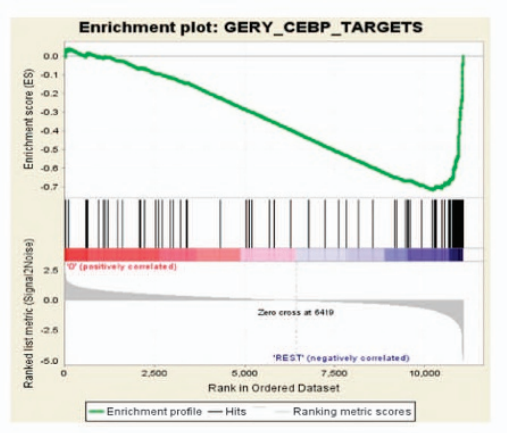

d

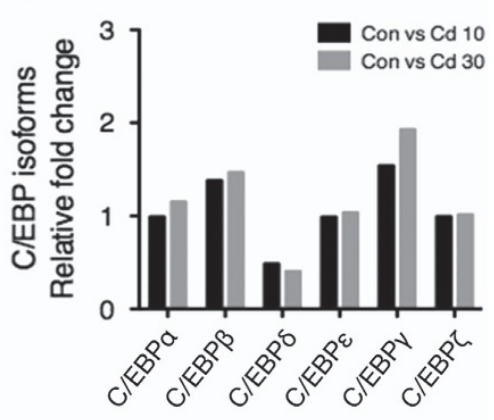

c
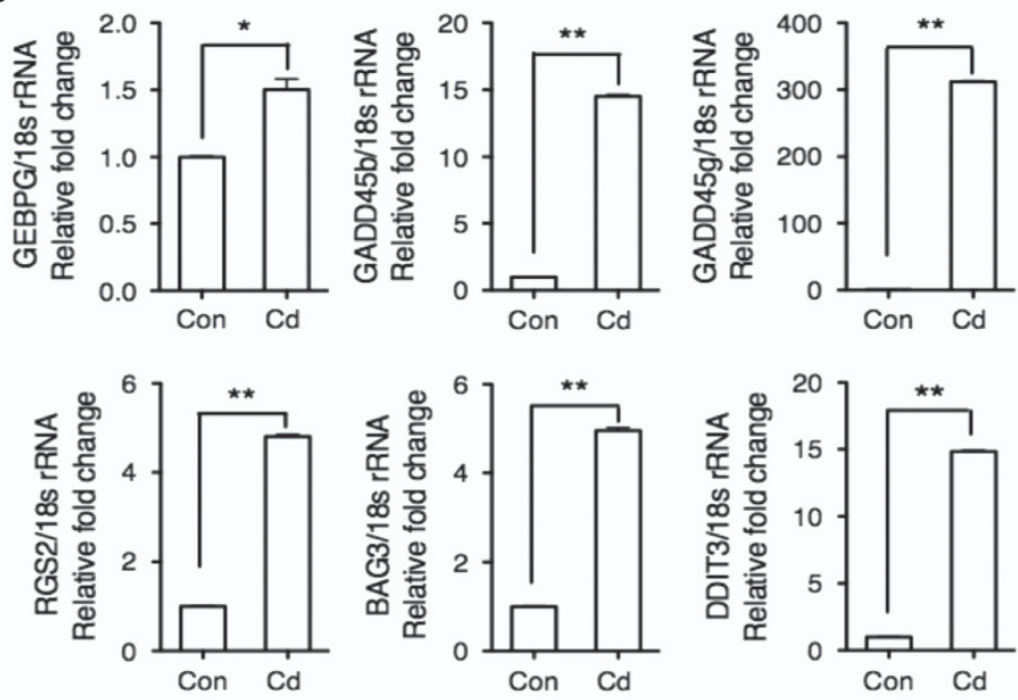

Figure 4 Collective upregulation of C/EBP target genes by cadmium (Cd) treatment. Heat map of genes in the 'C/EBP targets' gene set. The color spectrum from blue to red indicates low to high expression (a). Enrichment plot of the 'C/EBP targets' gene set. Genes within the green box in a are leading candidates for building enrichment scores in Cd-treated cells (Cd) (b). The results of real-time PCR for several genes included in the green box in a to measure the relative differences in their expression levels between Con and $\mathrm{Cd}$. ${ }^{*} P<0.05$; ${ }^{*} P<0.01$ (c). Real-time PCR analyses to evaluate expression levels of C/EBP family members in cells treated with Cd (d). Cd and Con indicate cells cultured with and without $\mathrm{Cd}$, respectively.

role of DDIT3 in the inflammatory response in human bronchial epithelial cells, BESA-2B cells were transfected with siRNA against the DDIT3 transcript. To test the efficiency of DDIT3 transcript suppression, BEAS-2B cells were transfected with $10 \mathrm{~nm}$ siRNA and cultured for $24 \mathrm{~h}$. Then, the cells were processed for western blot analysis to determine the expression of DDIT3. As expected, transfection of BEAS-2B cells with $10 \mathrm{~nm}$ siRNA resulted in $\sim 70 \%$ silencing of DDIT3 gene expression levels, compared with control (Supplementary Figure S3a). More importantly, the silencing of DDIT3 before the addition of $\mathrm{Cd}$ suppressed the inflammatory responses of BEAS-2B cells compared with Cd-treated control cells (Figure $5 \mathrm{a}-\mathrm{c}$ ). These results clearly showed that silencing of DDIT3 significantly protected against Cd-induced pro-inflammatory cytokine production in BEAS-2B cells. Next, we determined whether DDIT3 has an impact(s) on Cd-induced nuclear factor kappa B (NF- $\kappa \mathrm{B})$ activity. NF- $\kappa \mathrm{B}$ activity is controlled by the inhibitor of kappa B (IкB) complex. Under control conditions, p65 is sequestered in the cytosol by the I $\mathrm{BB}$ complex. Upon cytokine treatment, I $\mathrm{KB}-\alpha$ and $\beta$ are degraded, allowing p65 translocation to the nucleus and the induction of NF- $\kappa \mathrm{B}$ target genes. In an attempt to explain the effect of DDIT3 on NF- $\kappa$ B activity, we studied the impact of DDIT3 on p65 translocation and the stability of the I $\mathrm{KB}$ complex. Knockdown of DDIT3 attenuated p65 nuclear translocation induced by $\mathrm{Cd}$ toxicity and prevented I $\mathrm{KB}-\alpha$ degradation (Figure 5d). PI3K-Akt signaling has an important role in regulating cell growth, proliferation, survival and motility. ${ }^{18,19}$ Thus, we determined whether Cd toxicity is regulated through the Akt signaling pathway in a DDIT3-dependent manner. Knockdown of DDIT3 prevented the dephosphorylation of Akt (Ser473) induced by Cd treatment (Figure 5e). To reinforce the biological relevance of our findings in BEAS-2B cells exposed to $\mathrm{Cd}$, we examined whether $\mathrm{Cd}$ also provokes inflammatory responses via activation $\mathrm{C} / \mathrm{EBP}-\mathrm{DDIT} 3$ signaling in primary cultured NHBE cells. As seen in BEAS-2B cells, Cd induced 
a
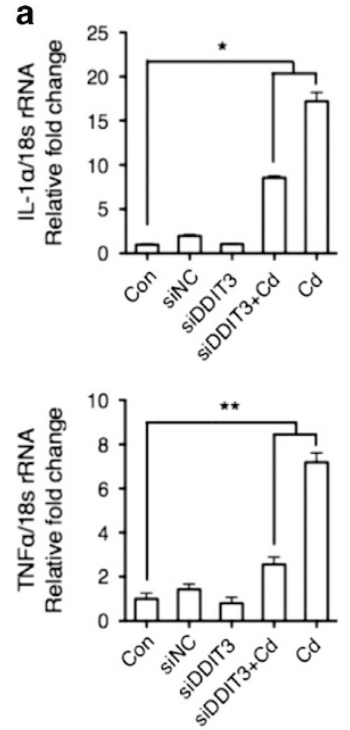

C

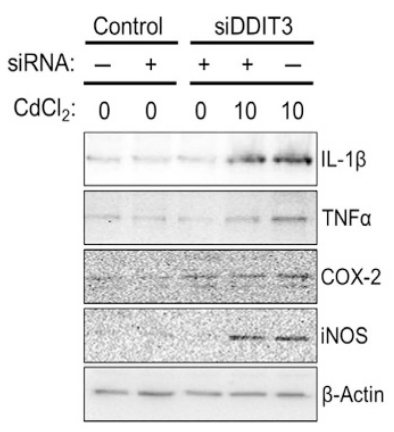

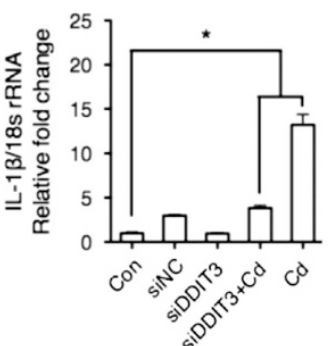
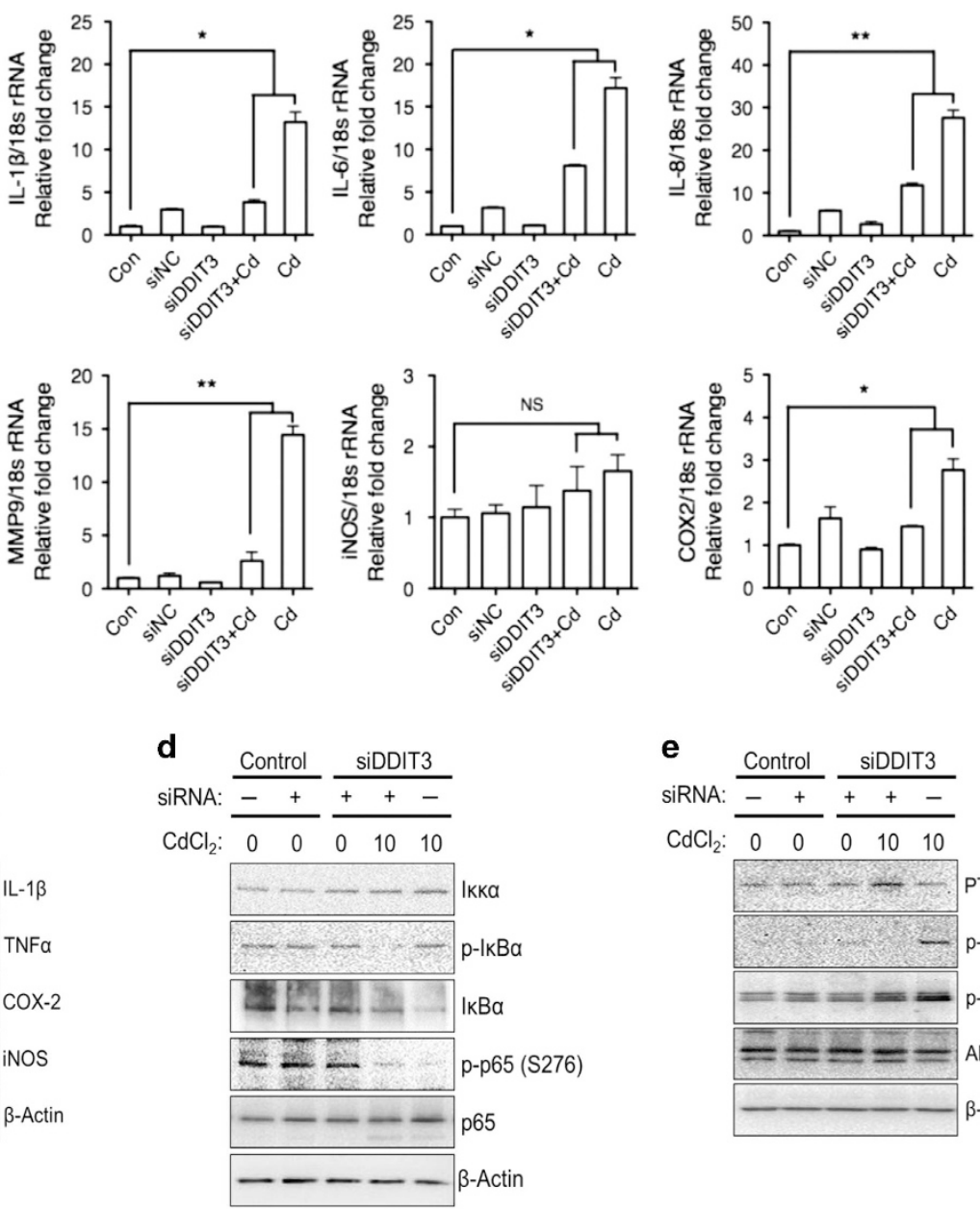

b
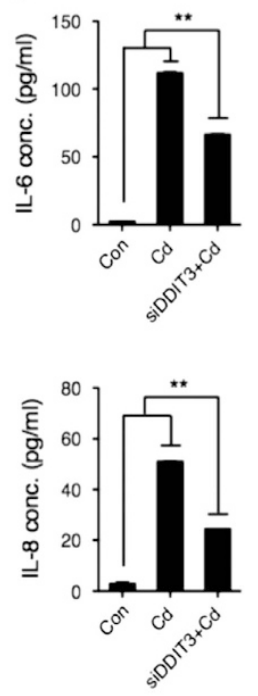

Figure 5 Effect of DDIT3 knockdown on the inflammatory response to cadmium (Cd) in BEAS-2B cells. BEAS-2B cells were transiently transfected with DDIT3 siRNA or a control, non-targeting siRNA (siNC). After incubation for $24 \mathrm{~h}$, the cells were treated with Cd (10 $\mu \mathrm{m})$ for $24 \mathrm{~h}$. Levels of pro-inflammatory cytokine mRNAs were analyzed by quantitative real-time PCR (a). Cell supernatants were subjected to ELISA to measure IL-6 or IL-8 levels (b). Cell lysates were subjected to western blot analysis to determine the protein level of IL-1 $\beta$, TNF $\alpha$, iNOS or COX2 (c) and NF-KB activity (d). The PTEN/AKT pathway was examined by western blotting (e). All data shown are representative of at least three biological replicates. ${ }^{*} P<0.05 ;{ }^{*} P<0.01$.

upregulation of $\mathrm{C} / \mathrm{EBPs}$ and their target genes, including GADD45b/g, RGS2, BAG3 and DDIT3 (Figure 6a and b). In addition, silencing of DDIT3 expression in NHBE cells suppressed inflammatory responses in a similar manner (Figure 6c; Supplementary Figure S3b). In conclusion, our study shows that $\mathrm{Cd}$ induces inflammatory cytokine secretion in human bronchial epithelial cells via the C/EBP-DDIT3 signaling pathway. DDIT3 directly contributes to Cd-induced cell apoptosis by promoting the activation of pro-apoptotic NF- $\kappa \mathrm{B}$-dependent pathways and Akt phosphorylation.

\section{DISCUSSION}

Previous studies have shown that $\mathrm{Cd}$ induces apoptotic cell death via the activation of ER stress-related signal transduction pathways in various cell types. ${ }^{9,10,20-25}$ Some of these studies demonstrated the pro-apoptotic role of DDIT3 in cells exposed to $\mathrm{Cd}$, which is mediated by ER stress and leads to cell death. For example, Cd-initiated apoptosis of human renal proximal tubular cells via the induction of DDIT3 is mediated by the activation of either ATF4 or ATF6. ${ }^{21,22} \mathrm{Cd}$ also induces the activation of DDIT3, ATF4 and ATF6 in rat cardiomyocytes and thus leads to cardiac cell death by disrupting glucose metabolism. ${ }^{25}$ The exposure of neuroblastoma cells to Cd leads to an increase in intracellular ROS generation, which results in cell death by DDIT3 induction. ${ }^{10}$ In addition, transcriptional activation of the DDIT3 promoter by Cd exposure in HepG2 hepatoma cells increases DNA damage and cell death. ${ }^{9}$ These results are consistent with our finding that DDIT3 is upregulated in Cd-treated human bronchial epithelial cells and induces cell death by stimulating pro-apoptotic and pro-inflammatory responses. Interestingly, $\mathrm{As}$ and $\mathrm{Cr}$ also elevate the transcriptional and translational activation of DDIT3 and ER stress in liver cells via the upregulation of the ATF5 and ATF6 genes and lead to cell death. ${ }^{24,26}$ These findings together indicate that DDIT3 could be a common cytotoxic marker induced by exposure to toxic heavy metals, as 
a
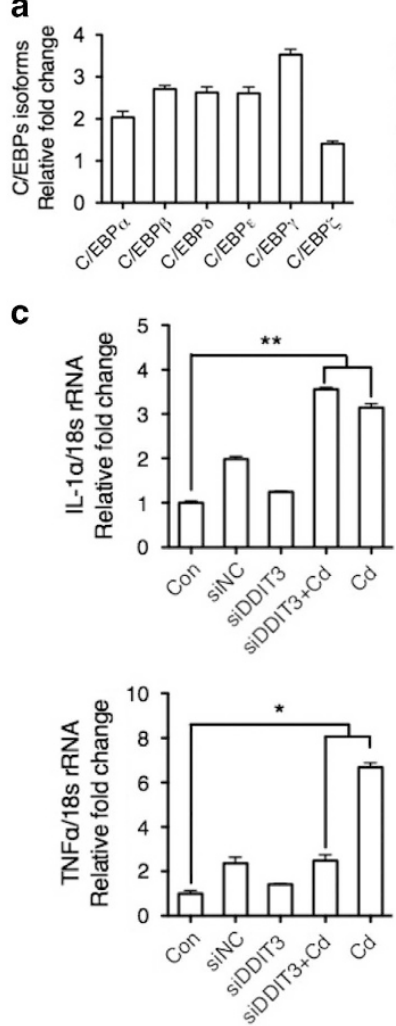

b
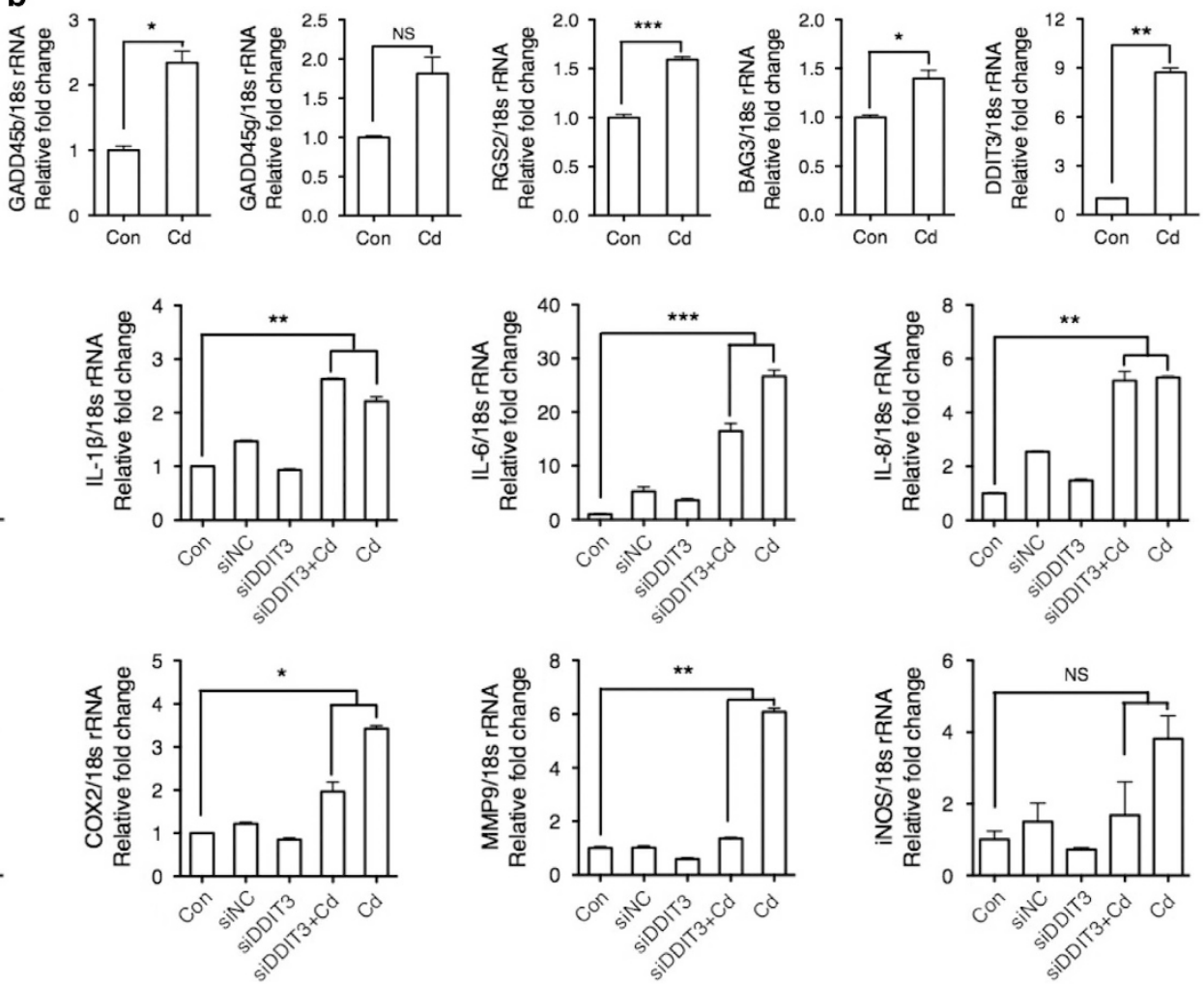

Figure 6 Effect of DDIT3 knockdown on the inflammatory response to Cd in primary normal human bronchial epithelial (NHBE) cells. Expression levels of C/EBP family members in cells treated with Cd (a). Expression levels of C/EBP target genes between Con and Cd. (b). Primary NHBE cells were transiently transfected with DDIT3 siRNA or non-targeting siRNA (siNC). After incubation for $24 \mathrm{~h}$, the cells were treated with $\mathrm{Cd}(10 \mu \mathrm{m})$ for $24 \mathrm{~h}$. Levels of pro-inflammatory cytokine mRNAs were analyzed by quantitative real-time PCR (c). All data shown are representative of at least three biological replicates. ${ }^{*} P<0.05 ;{ }^{*} P<0.01,{ }^{* * *} P<0.001$.

well as a molecular target for blocking apoptotic cell death and for the treatment of pulmonary diseases including COPD. ATFs are known as ER stress transducers that function to initiate the UPR and regulate DDIT3 expression in cells exposed to a toxic environment, and their functions may be cell type-specific. ${ }^{27}$ In our current finding, ATF4 and ATF5 were strongly upregulated in Cd-treated BEAS-2B cells, suggesting that DDIT3 is a potential target for ATF4 or ATF5. We also found that knockdown of the DDIT3 transcript attenuated secretion of IL- 8 and p 65 nuclear translocation induced by $\mathrm{Cd}$ toxicity, suggesting that the NF- $\kappa \mathrm{B}$ signaling pathway may be involved in the inflammatory response and cell death upon $\mathrm{Cd}$ exposure of human airway epithelial cells. ${ }^{12}$ In contrast, NF- $\kappa B$-independent secretion of IL-8 in human airway epithelial cells exposed to $\mathrm{Cd}$ has been reported. ${ }^{14}$ Thus, further study will be needed to reveal the regulatory role of ATF4, ATF5 and NF-кB-signaling pathway in Cd-induced inflammatory responses, which may provide the exact molecular mechanisms underlying the initiation and development of pulmonary diseases upon Cd exposure.

Our GSEA revealed that the 'C/EBP_targets' gene set is significantly upregulated in Cd-treated BEAS-2B cells. DDIT3 is included in this gene set as a C/EBP downstream target. We further confirmed that the suppression of DDIT3 using siRNA alleviated the inflammatory and ER stress responses elevated by $\mathrm{Cd}$ exposure, suggesting that the C/EBP-DDIT3 signaling pathway could be a therapeutic target for the treatment of pulmonary diseases including COPD. The precise role of C/EBP genes in the initiation and development of COPD remains unclear. However, several studies indicate that C/EBP transcription factors are primarily responsible for ER stress and inflammation-related gene expression and might be implicated in COPD. For example, Mori et al. ${ }^{28}$ reported elevated expression of C/EBP $\beta$ in advanced COPD patients compared with the asymptomatic smokers. Elevated expression of $\mathrm{C} / \mathrm{EBP} \beta$ induces the downregulation of elastin mRNA in lung alveoli because $\mathrm{C} / \mathrm{EBP} \beta$ acts as a negative regulator of elastin transcription. ${ }^{29}$ Similar to these results, our study detected increased expression of $\mathrm{C} / \mathrm{EBP} \beta$ in BEAS-2B cells treated with $\mathrm{Cd}$. These findings suggest that an increased C/EBP $\beta$ level may correlate with the destruction of normal lung function and structure in COPD patients. In contrast, Didon et al. ${ }^{30}$ reported that the binding activity of $\mathrm{C} / \mathrm{EBP} \beta$ in the airway epithelium is decreased in COPD patients compared with healthy smokers. They further reported that C/EBP $\beta$ expression is significantly downregulated in the airway epithelial cells of smokers compared with those who had never been smokers and in primary human bronchial epithelial cell cultures treated with 
cigarette smoke extract (CSE). Furthermore, CSE treatment caused compromised induction of pro-inflammatory cytokines and neutrophil chemoattractants in $\mathrm{C} / \mathrm{EBP} \beta$-inactivated mouse lung epithelial cells. ${ }^{31}$ These results suggest that decreased expression of $\mathrm{C} / \mathrm{EBP} \beta$ might render the lung epithelium resistant to efficient regeneration and more sensitive to irritant toxic materials. The identification of two different regulatory pathways for $\mathrm{C} / \mathrm{EBP} \beta$ translation may be the cause of this discrepancy between these studies. ${ }^{32,33}$ Another possibility is that the activity of $\mathrm{C} / \mathrm{EBP} \beta$ can be regulated by other $\mathrm{C} / \mathrm{EBP}$ family members, especially $\mathrm{C} / \mathrm{EBP} \gamma \cdot \mathrm{C} / \mathrm{EBP} \gamma$ is a truncated isoform that appears to lack the N-terminal activation domains present in most other C/EBP family members. ${ }^{34,35}$ Under physiological and pathophysiological conditions, C/EBP $\gamma$ serves as a regulator or reservoir against the transcription activity of C/EBP family members through heterodimerization. ${ }^{36}$ Recent studies have provided evidence that $\mathrm{C} / \mathrm{EBP} \gamma$ is an important regulator of airway epithelial proliferation, apoptosis and development. $^{36,37}$ Interestingly, in our study, among all members of the C/EBP family, C/EBP $\gamma$ was the most significantly increased upon treatment with 10 and $30 \mu \mathrm{M} \mathrm{Cd}$ ( $\sim$ twofold). In fact, in silico analyses for the DDIT3 promoter suggest that putative-binding sites for both $\mathrm{C} / \mathrm{EBP} \beta$ and $\mathrm{C} / \mathrm{EBP} \gamma$ are present in the proximal region of conserved DDIT3 promoters (data not shown). Although further studies are needed, it is conceivable that regulation of $\mathrm{C} / \mathrm{EBP} \gamma$ expression may result in improvements for the treatment of COPD by controlling the activity of both the C/EBP $\alpha$ and $\mathrm{C} / \mathrm{EBP} \beta$ proteins.

In summary, our study extends and further integrates present knowledge regarding the molecular mechanisms linking Cd-induced ER stress and inflammatory responses to pulmonary diseases. Insights into the network regulating DDIT3-mediated apoptosis and the inflammatory response will potentially provide a basis for C/EBP-DDIT3 signaling-targeted therapeutic approaches to ER stress-associated pulmonary diseases.

\section{CONFLICT OF INTEREST}

The authors declare no conflict of interest.

\section{ACKNOWLEDGEMENTS}

This study was supported by grants from the Environmental Health Center funded by the Ministry of Environment, Republic of Korea and Global PhD Fellowship Program through the National Research Foundation of Korea (NRF) funded by the Ministry of Education (2016H1A2A1909769).

1 Underner M, Perriot J, Peiffer G. Smoking cessation in smokers with chronic obstructive pulmonary disease. Rev Mal Respir 2014; 31: 937-960.

2 Lee JY, Rhee CK, Jung KS, Yoo KH. Strategies for management of the early chronic obstructive lung disease. Tuberc Respir Dis (Seoul) 2016; 79: 121-126.

3 Durham AL, Adcock IM. The relationship between COPD and lung cancer. Lung Cancer 2015; 90: 121-127.
4 Mannino DM, Holguin F, Greves HM, Savage-Brown A, Stock AL, Jones RL. Urinary cadmium levels predict lower lung function in current and former smokers: data from the Third National Health and Nutrition Examination Survey. Thorax 2004; 59: 194-198.

$5 \mathrm{Lim}$ SC, Hahm KS, Lee SH, Oh SH. Autophagy involvement in cadmium resistance through induction of multidrug resistance-associated protein and counterbalance of endoplasmic reticulum stress WI38 lung epithelial fibroblast cells. Toxicology 2010; 276: 18-26.

6 Xu YM, Wu DD, Zheng W, Yu FY, Yang F, Yao Y et al. Proteome profiling of cadmium-induced apoptosis by antibody array analyses in human bronchial epithelial cells. Oncotarget 2016; 7: 6146-6158.

$7 \mathrm{Ma} \mathrm{Y}$, Hendershot LM. ER chaperone functions during normal and stress conditions. J Chem Neuroanat 2004; 28: 51-65.

8 Schroder M, Kaufman RJ. ER stress and the unfolded protein response. Mutat Res 2005; 569: 29-63.

9 Zhang R, Niu YJ, Zhang ZJ, Chen Q, Guo HC, Zhao J et al. The effects of the cadmium chloride on the DNA damage and the expression level of gadd gene in HepG2 cell line. Zhonghua Lao Dong Wei Sheng Zhi Ye Bing Za Zhi 2011; 29: 409-412.

10 Kim S, Cheon HS, Kim SY, Juhnn YS, Kim YY. Cadmium induces neuronal cell death through reactive oxygen species activated by GADD153. BMC Cell Biol 2013; 14: 4.

11 Oyadomari S, Mori M. Roles of CHOP/GADD153 in endoplasmic reticulum stress. Cell Death Differ 2004; 11: 381-389.

12 Napolitano JR, Liu MJ, Bao S, Crawford M, Nana-Sinkam P, Cormet-Boyaka $E$ et al. Cadmium-mediated toxicity of lung epithelia is enhanced through NF-kappaB-mediated transcriptional activation of the human zinc transporter ZIP8. Am J Physiol Lung Cell Mol Physiol 2012; 302: L909-L918.

13 Cox JN, Rahman MA, Bao S, Liu M, Wheeler SE, Knoell DL. Cadmium attenuates the macrophage response to LPS through inhibition of the NF-kappaB pathway. Am J Physiol Lung Cell Mol Physiol 2016; 311: L754-L765.

14 Cormet-Boyaka E, Jolivette K, Bonnegarde-Bernard A, Rennolds J, Hassan F, Mehta $\mathrm{P}$ et al. An NF-kappaB-independent and Erk1/2-dependent mechanism controls CXCL8/IL- 8 responses of airway epithelial cells to cadmium. Toxicol Sci 2012; 125: 418-429.

15 Li GY, Kim M, Kim JH, Lee MO, Chung JH, Lee BH. Gene expression profiling in human lung fibroblast following cadmium exposure. Food Chem Toxicol 2008; 46: 1131-1137.

16 Subramanian A, Tamayo P, Mootha VK, Mukherjee S, Ebert BL, Gillette MA et al. Gene set enrichment analysis: a knowledge-based approach for interpreting genome-wide expression profiles. Proc Natl Acad Sci USA 2005; 102: 15545-15550.

17 Koedrith P, Kim HL, Seo YR. Integrative toxicogenomics-based approach to risk assessment of heavy metal mixtures/complexes: strategies and challenges. Mol Cell Toxicol 2015; 11: 265-276.

18 Davis WJ, Lehmann PZ, Li W. Nuclear PI3K signaling in cell growth and tumorigenesis. Front Cell Dev Biol 2015; 3: 24.

19 Seo J-Y, Lee Y-J, Oh M-H, Lee S-H. In vitro nasal epithelial toxicity by cadmium accompanies up-regulation of RUNX3 protein with activation of PI3-kinase/Akt. Mol Cell Toxicol 2013; 9: 159-167.

$20 \mathrm{Ji}$ YL, Wang H, Zhang C, Zhang Y, Zhao M, Chen YH et al. N-acetylcysteine protects against cadmium-induced germ cell apoptosis by inhibiting endoplasmic reticulum stress in testes. Asian J Androl 2013; 15: 290-296.

21 Komoike $\mathrm{Y}$, Inamura H, Matsuoka M. Effects of salubrinal on cadmiuminduced apoptosis in HK-2 human renal proximal tubular cells. Arch Toxicol 2012; 86: 37-44.

22 Yokouchi M, Hiramatsu N, Hayakawa K, Kasai A, Takano Y, Yao J et al. Atypical, bidirectional regulation of cadmium-induced apoptosis via distinct signaling of unfolded protein response. Cell Death Differ 2007; 14: 1467-1474.

23 Chakraborty PK, Lee WK, Molitor M, Wolff NA, Thevenod F. Cadmium induces Wnt signaling to upregulate proliferation and survival genes in sub-confluent kidney proximal tubule cells. Mol Cancer 2010; 9: 102.

24 Yamazaki T, Ohmi A, Kurumaya H, Kato K, Abe T, Yamamoto H et al. Regulation of the human $\mathrm{CHOP}$ gene promoter by the stress response transcription factor ATF5 via the AARE1 site in human hepatoma HepG2 cells. Life Sci 2010; 87: 294-301.

25 Chen CY, Zhang SL, Liu ZY, Tian Y, Sun Q. Cadmium toxicity induces ER stress and apoptosis via impairing energy homoeostasis in cardiomyocytes. Biosci Rep 2015; 35: e00214. 
26 Jin Y, Zhang S, Tao R, Huang J, He X, Qu L et al. Oral exposure of mice to cadmium (II), chromium (VI) and their mixture induce oxidative- and endoplasmic reticulum-stress mediated apoptosis in the livers. Environ Toxicol 2016; 31: 693-705.

27 Lu W, Hagiwara D, Morishita Y, Tochiya M, Azuma Y, Suga H et al. Unfolded protein response in hypothalamic cultures of wild-type and ATF6alpha-knockout mice. Neurosci Lett 2016; 612: 199-203.

28 Mori M, Bjermer L, Erjefalt JS, Stampfli MR, Roos AB. Small airway epithelial-C/EBPbeta is increased in patients with advanced COPD. Respir Res 2015; 16: 133.

29 Kuang PP, Goldstein RH. Regulation of elastin gene transcription by interleukin-1 beta-induced C/EBP beta isoforms. Am J Physiol Cell Physiol 2003; 285: C1349-C1355.

30 Didon L, Qvarfordt I, Andersson O, Nord M, Riise GC. Decreased CCAAT/ enhancer binding protein transcription factor activity in chronic bronchitis and COPD. Chest 2005; 127: 1341-1346.

31 Didon L, Barton JL, Roos AB, Gaschler GJ, Bauer CM, Berg T et al. Lung epithelial CCAAT/enhancer-binding protein-beta is necessary for the integrity of inflammatory responses to cigarette smoke. Am J Respir Crit Care Med 2011; 184: 233-242.

32 Miglino N, Roth M, Tamm M, Borger P. House dust mite extract downregulates C/EBPalpha in asthmatic bronchial smooth muscle cells. Eur Respir J 2011; 38: 50-58.

33 Borger $\mathrm{P}$, Koeter GH, Timmerman JA, Vellenga E, Tomee JF, Kauffman HF. Proteases from Aspergillus fumigatus induce interleukin (IL)- 6 and IL-8 production in airway epithelial cell lines by transcriptional mechanisms. $\mathrm{J}$ Infect Dis 1999; 180: 1267-1274.

34 Lundgren M, Larsson C, Femino A, Xu M, Stavnezer J, Severinson E. Activation of the Ig germ-line gamma 1 promoter. Involvement of
C/enhancer-binding protein transcription factors and their possible interaction with an NF-IL-4 site. J Immunol 1994; 153: 2983-2995.

35 Cooper C, Henderson A, Artandi S, Avitahl N, Calame K. Ig/EBP (C/EBP gamma) is a transdominant negative inhibitor of C/EBP family transcriptional activators. Nucleic Acids Res 1995; 23: 4371-4377.

36 Huggins CJ, Malik R, Lee S, Salotti J, Thomas S, Martin N et al. $\mathrm{C} /$ EBPgamma suppresses senescence and inflammatory gene expression by heterodimerizing with C/EBPbeta. Mol Cell Biol 2013; 33: 3242-3258.

37 Mullins DN, Crawford EL, Khuder SA, Hernandez DA, Yoon Y, Willey JC. CEBPG transcription factor correlates with antioxidant and DNA repair genes in normal bronchial epithelial cells but not in individuals with bronchogenic carcinoma. BMC Cancer 2005; 5: 141.

Attribution-NonCommercial-NoDerivs 4.0 International License. The images or other third party material in this article are included in the article's Creative Commons license, unless indicated otherwise in the credit line; if the material is not included under the Creative Commons license, users will need to obtain permission from the license holder to reproduce the material. To view a copy of this license, visit http://creativecommons.org/licenses/by-nc-nd/4.0/

C) The Author(s) 2017

Supplementary Information accompanies the paper on Experimental \& Molecular Medicine website (http://www.nature.com/emm) 